\title{
New Reagent for Coupling Reaction and Spectrophotometric Determination of Paracetamol in Pharmaceutics
}

\author{
KURDISTAN F. AZEEZ ${ }^{1}$, TARA F. TAHIR ${ }^{1 *}$ and DASHNE M. KOKHASMAIL ${ }^{1}$ \\ 'Department of Chemistry, Faculty of Science and Health, Koya University, \\ Koya KOY45, Kurdistan Region-F. R. Iraq. \\ *Corresponding author E-mail: tara.fuad@koyauniversity.org \\ http://dx.doi.org/10.13005/ojc/370416
}

(Received: June 20, 2021; Accepted: August 18, 2021)

\begin{abstract}
New reagent 2-hydroxybenzaldehyde was used in a coupling reaction for determination of paracetamol via spectrophotometric method. The proposition of simplicity, inexpensive, rapidity and sensitivity were conducted via spectrophotometric procedure. The method is based on diazotization of paracetamol and coupling with 2-hydroxybenzaldehyde in alkaline medium. Linear concentration range (0.50-12.00) $\mu \mathrm{g} / \mathrm{mL}$ was comply Beer's law at maximum wavelength $444 \mathrm{~nm}$ and detection limit (LOD) $0.05 \mu \mathrm{g} / \mathrm{mL}$. The molar absorptivity and regression coefficient of $\left(R^{2}\right)$ were $1.2032 \times 10^{4}$ $\mathrm{l} / \mathrm{mol} . \mathrm{cm}, 0.9995$, respectively. The suggested method was profitably adapted for the determination of paracetamol in pharmaceutics. The results attained were in good agreement with that one by standard method high performance liquid chromatography (HPLC).
\end{abstract}

Keywords: Coupling reaction, Paracetamol, Azo dyes, Spectrophotometric method, 2-hydroxybenzaldehyde.

INTRODUCTION

The most common analgesic and antipyretic compound have been used in therapy is paracetamol, since 1950. Paracetamol is considered as one of the crucial human medicine that has therapeutic properties as well as it causes hepatotoxicity when it is overdosed, and this has confirmed by $\mathrm{WHO}^{1}$.

Poisoning by paracetamol is likely virulent. The essential source of cytolytic hepatitis is $\mathrm{N}$-acetyl-p-benzoquinone-imine, which is a harmful metabolite of paracetamol, that is leading to dose-dependent hepatocyte necrosis and death in many countries ${ }^{2,3}$.
High performance liquid chromatography is the most periodically technique used for evaluation of paracetamol in pharmaceutics, however still spectrophotometer technique is very popular in this field ${ }^{4}$. Hyphenated techniques such as chromatographic HPLC method with UV or MS are specific and sensitive technique but they are taking more time in the analysis and more costly, 5 . UV-Visible spectrophotometer has been used for direct and indirect determination of paracetamol based mainly on a coloured product resulted from the reaction of chromogenic reagent with paracetamol. There are other visible spectrophotometric methods in which paracetamol submitted to specific reactions

This is an Open Access article licensed under a Creative Commons license: Attribution 4.0 International (CC- BY). Published by Oriental Scientific Publishing Company @ 2018

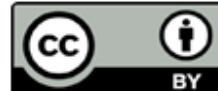


to produce a coloured derivative directly, or sometimes indirectly. A few of these methods enclose laborious steps such as extraction, heating, and $\mathrm{pH}$ controlling ${ }^{7}$. Azo coupling reaction is the most prominent visible spectrophotometric methods for determination of paracetamol and its derivative (para aminophenol). Their attractivity is related to the ease of preparation and fast production, besides their wide range of shades ${ }^{8}$.

This work is to optimize and endorse a UV-Visible spectrophotometric method based on a new azo reaction for determination of paracetamol in pharmaceutics, that feasible in the situation of limited resources in laboratories.

\section{MATERIALS AND METHODS}

\section{Instrumentation}

Agilent Technologies Cary Series, UVVisible spectrophotometer, double beam is used and equipped with a glass cell of $\mathrm{a} \mathrm{cm}^{-1}$ optical path. Agilent 1100 HPLC instrument regulated by a system of Chemstation Data with a quaternary pump G1311A and VWD-G1314 A of UV detector. The operation condition of the last system is a $\mathrm{C} 18$ column reverse phase of $300 \mathrm{~mm} \times 4.6 \mathrm{~mm}, 5 \mu \mathrm{m}$ ). Trifluoroacetic acid $(0.1 \% \mathrm{v} / \mathrm{v})$ and acetonitrile are used as mobile phase with ratio $(80: 20 \mathrm{v} / \mathrm{v})$.

\section{Chemicals and reagents}

Acetic acid \%99.9 $\left(\mathrm{CH}_{3} \mathrm{COOH}\right)$, methanol $\% 99.7\left(\mathrm{CH}_{3} \mathrm{OH}\right)$ and sulfuric acid \%98 $\left(\mathrm{H}_{2} \mathrm{SO}_{4}\right)$ from Merk. Calcium carbonate $\left(\mathrm{CaCO}_{3}\right) \% 98$ and 2-hydroxy benzaldehyde $\left(\mathrm{C}_{7} \mathrm{H}_{6} \mathrm{O}_{2}\right) \% 99.9$ from Sigma Aldrich. Potassium hydroxide \%85 $(\mathrm{KOH})$, sodium nitrite \%99.5 $\left(\mathrm{NaNO}_{2}\right)$ and sodium carbonate \%99.5 $\left(\mathrm{Na}_{2} \mathrm{CO}_{3}\right)$ from Riedel-De Haen AG. Hydrochloric acid \%36.5 $(\mathrm{HCl})$ from $\mathrm{E}$. U. Magnesium stearate $\% 99 \mathrm{Mg}\left(\mathrm{C}_{18} \mathrm{H}_{35} \mathrm{O}_{2}\right)_{2}$ from BDH. Nitric acid \%70 $\left(\mathrm{HNO}_{3}\right)$ from Scharlau. Sodium hydroxide $(\mathrm{NaOH})$ from SCP and starch from Difco. Pure paracetamol standard \%99.99 from Awamedica-Erbil//raq.

\section{Preparation of reagents and standard stock solution}

2-Hydroxybenzaldehyde, $1.0 \%(\mathrm{w} / \mathrm{v})$ in methanol. Sodium nitrite, $1.0 \%(\mathrm{w} / \mathrm{v})$ aqueous solution. Hydrochloric acid, $(0.1,4 \mathrm{M})$ aqueous solution, individually. Sodium hydroxide, $1.0 \%(\mathrm{w} / \mathrm{v})$ aqueous solution. Starch, $0.1 \%(\mathrm{w} / \mathrm{v})$ hot aqueous solution. $0.1 \%(\mathrm{w} / \mathrm{v})$ calcium carbonate, in $0.1 \mathrm{M}$ hydrochloric acid aqueous solution. Magnesium stearate, $0.1 \%$ $(w / v)$ in a mixture of ether $(50 \mathrm{~mL})$, nitric acid $(20 \mathrm{~mL})$ and distilled water $(20 \mathrm{~mL})$. The mixture is refluxed until it is completely dissolved, then cool down. $0.25 \mathrm{~g}$ of standard paracetamol powder is refluxed with $20 \mathrm{~mL} \mathrm{HCl}(4 \mathrm{M})$ and distilled water $(30 \mathrm{~mL})$ of for $30 \mathrm{~min}$ to prepare $5000 \mu \mathrm{g} / \mathrm{mL}$ working standard solution of paracetamol ${ }^{9}$.

\section{Preparation of samples}

Pharmaceutical products of three various brands (each one contains $500 \mathrm{mg}$ paracetamol) are weighed and grind into a fine powder then mix thoroughly. Powder mixture that contains $0.0664 \mathrm{~g}$ powder Piodol (Pioneer-Iraq/Sulaymaniyah), 0.0613 g powder Paracetol (M.D.I-Iraq/Baghdad) and 0.0599 g Parazar (Awamedica-Iraq/Erbil) of paracetamol are weighed accurately, then mixed with $20 \mathrm{~mL} \mathrm{HCl}(4 \mathrm{M})$, distilled water $(30 \mathrm{~mL})$ and mixed for 10 minute. The mixture is filtered using filter-paper (Whatman No.41), to remove insoluble and is washed with methanol. The filtrate and the washing solution are diluted with distilled water into $50 \mathrm{~mL}$ volumetric flask ${ }^{10}$.

\section{Methods}

Performing procedure is based on azo dyes method, which comprises two steps; first step is formation of a diazonium salt, and the second step is coupling reaction of the resulted diazonium salt with a coupling agent ${ }^{8}$.

The operating method is as follows: $1.0 \mathrm{~mL}$ hydrochloric acid $(0.1 \mathrm{M})$ is added into $10 \mathrm{~mL}$ volumetric flask that is contained $1.5 \mathrm{~mL}$ sodium nitrite $(1.0 \%)$. After stirring, the prepared paracetamol solution is added to the mixture at temperature below $5^{\circ} \mathrm{C}$ in ice bath. After shaking for $2 \mathrm{~min}, 1.0 \mathrm{~mL}$ sodium hydroxide (1.0\%) are poured followed by $1.0 \mathrm{~mL}$ 2-hyrdoxybanzaldehyde (1.0\%) while mixing in the ice bath. The yellow colour gained is recorded at $444 \mathrm{~nm}$ vs the blank reagent of hydrochloric acid, sodium nitrite, sodium hydroxide and 2-hyrdoxybanzaldehyde mixture (Scheme 1).

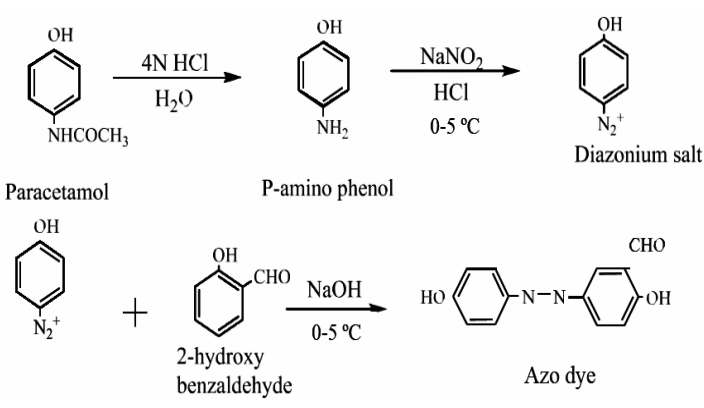

Scheme 1. Steps of the operation protocol method of azo dyes 
The spectrum of paracetamol solution showed that the absorbance got maximum at $\kappa_{\max }$ $243 \mathrm{~nm}$ while the absorbance of the prepared azo dye solution was measured at its maximum wavelength of $444 \mathrm{~nm}$ against blank solution (Figure 1 ).
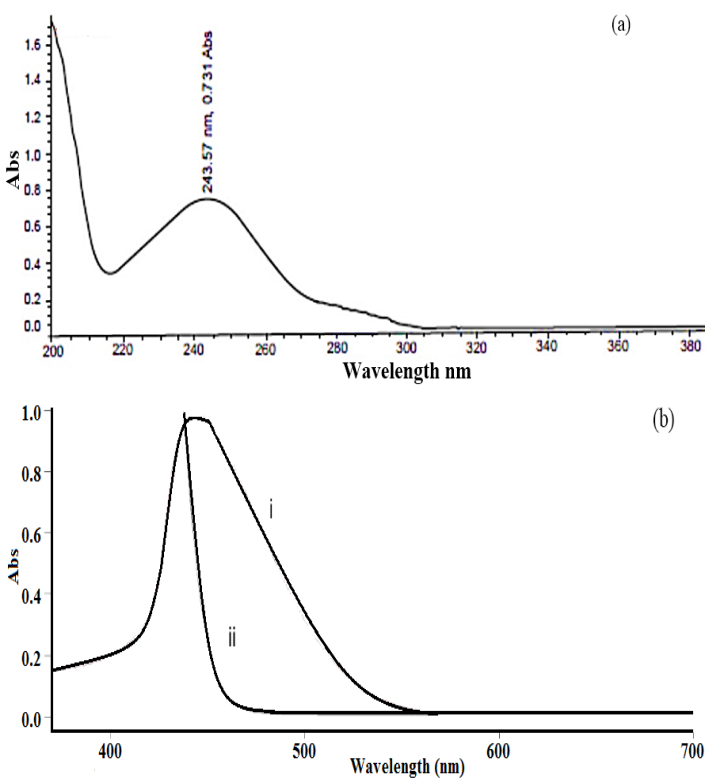

Fig. 1. Absorption spectra of (a) paracetamol, (b)-i- azo dye paracetamol-2-HBA, -ii- blank reagent vs distilled water

Optimizations were implemented on operating protocol described above regarding different chemicals of concentrations and volumes.

\section{Optimization}

\section{Chemical optimization}

Among sort of acids, hydrochloric acid had highest absorbance of 0.8273 at maximum volume $1.0 \mathrm{~mL}$ (Fig. 2). Increasing acid volume is resulted in the absorbance increase, while after $1 \mathrm{~mL}$ acid volume the excess acid is converted the diazonium ion to $\left(\mathrm{Ar}-\mathrm{NH}^{+} \mathrm{Cl}\right)$ diazonium salts and the absorbance is decreased ${ }^{11}$.

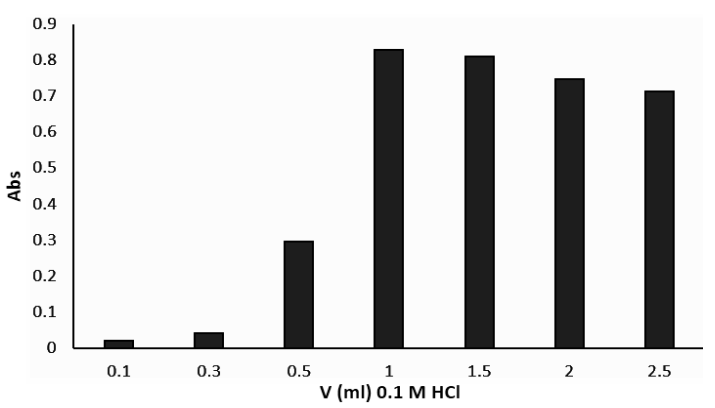

Fig. 2. Decreasing the absorbance upon increasing volume of $0.1 \mathrm{M} \mathrm{HCl}$ after $1.0 \mathrm{~mL}$
Figure 3 indicates that sodium nitrite $(1.0 \%)$ solution of $1.5 \mathrm{~mL}$ is enough to obtain a maximum absorption to convert $\mathrm{NH}_{2}$ group of $\mathrm{p}$-amino phenol to diazonium salt in the subsequent experiments ${ }^{11}$.

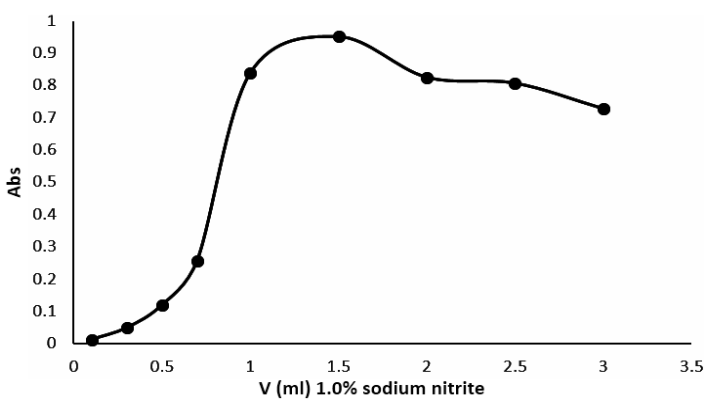

Fig. 3. Decreasing the absorbance upon increasing volume of $1.0 \%$ sodium nitrite after $1.5 \mathrm{~mL}$

Amount of $1.0 \mathrm{~mL} 2$-hydroxy benzaldehyde $(1.0 \%)$ solution was used in the subsequent experiments due to the increasing of amount of azo dye that is formed in the solution (Figure 4).

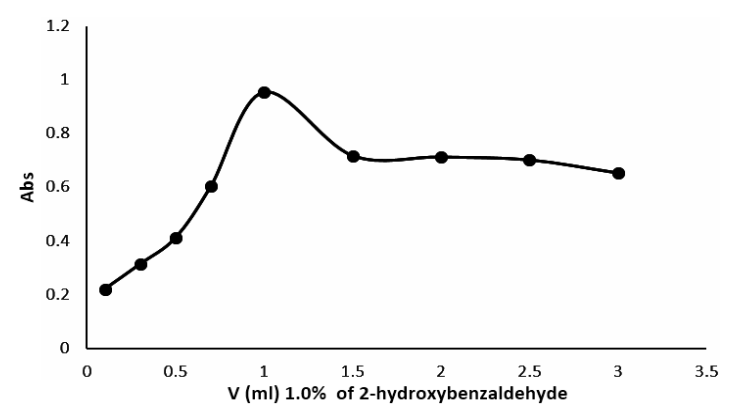

Fig. 4. Maximum absorbance at $1.0 \mathrm{~mL}$ sodium nitrite (1.0\%)

A solution of sodium hydroxide (1.0\%) was fulfilled for coupling reaction of diazonium ion salt with 2-hydroxy benzaldehyde, among other bases like potassium hydroxide and sodium carbonate. Fig. 5 indicates the maximum absorption at $1.0 \mathrm{~mL}$ sodium hydroxide solution (1.0\%) because the excess of hydroxide ion reacts with the reagent (the diazonium ion $\mathrm{ArN}^{2+}$ ) and tends to convert it to a non-ionized compound $\left(\mathrm{ArN}_{2} \mathrm{OH}\right)$ that do not couple with 2-hydroxy benzaldehyde ${ }^{11}$.

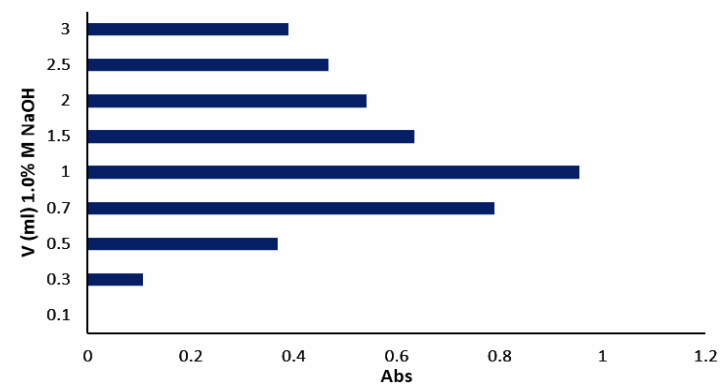

Fig. 5. Maximum absorbance at $1.0 \mathrm{ml}$ sodium hydroxide solution $(1.0 \%)$ 


\section{Physical optimization}

A maximum intensity 0.9535 of colored azo dye is reached as the reagent of coupling was poured to the diazonium ion solution and after 2 min of standing period. Reduced absorbance $0.6327,0.6683,0.6491$ and 0.6118 detected when the standing time of $1,3,4$ and 5 min were, respectively.

Temperature and time are crucial factor of azo dye stability ${ }^{12}$. Temperatures of ice bath $(0-5)^{\circ} \mathrm{C}$ as well as room temperature $(25 \pm 2)^{\circ} \mathrm{C}$ are applied in the reaction of diazotization. Maximum absorbance, 0.9542 indicated in ice bath since diazonium salt decomposes above temperatures of $5^{\circ} \mathrm{C}^{8}$. Time is pivotal for preparation and absorbance reporting. Instant development of the yellow color of azo dye is developed which remains stable for $1 \mathrm{~h}$ (Figure 6).

\section{Analytical parameters}

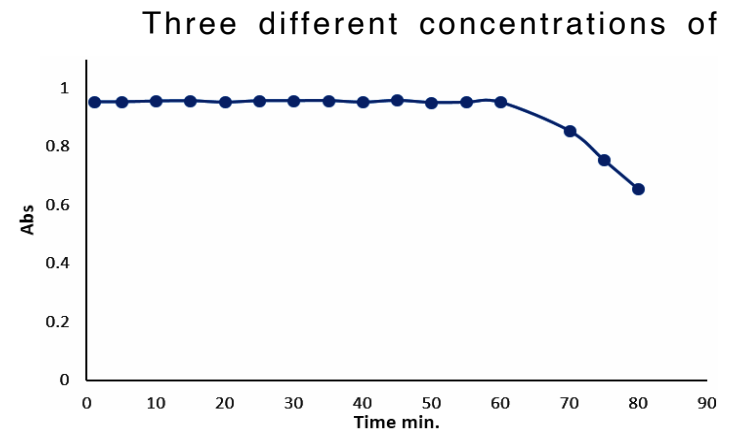

Fig. 6. Stability of azo dye represented via absorbance versus time paracetamol were chosen with five replications measurements for each of them to calculate relative standard deviation. Maximum RSD\% of $0.48 \%$ was attained of paracetamol under optimized experimental conditions ${ }^{13}$ (Table 1). Linearity of the calibration curve was adhered to Beer's law in the concentration range $(0.50-12.00) \mu \mathrm{g} / \mathrm{mL}$ with detection limit $0.05 \mu \mathrm{g} / \mathrm{mL}$ (Fig. 7). The molar absorptivity and regression coefficient $\left(R^{2}\right)$ were $1.2032 \times 10^{4} \mathrm{l} / \mathrm{mol} . \mathrm{cm}$ and 0.9995 , respectively.

In the suggested procedure, accuracy and precision was afforded via absorbance measurements of the azo dyes of the diazonium salt for paracetamol of three different concentrations $(0.50,6.00$ and $12.00 \mu \mathrm{g} / \mathrm{mL})$, individually of five replicate measurements for each one (Table 1). Values between $0.01 \%-0.48 \%$ and $-1.70 \%-2.00 \%$, were recorded of $\mathrm{RSD} \%$ and $\mathrm{E} \%$ respectively. The validity and applicability of the suggested procedure are indicated from RSD\% and $\mathrm{E} \%$ values.

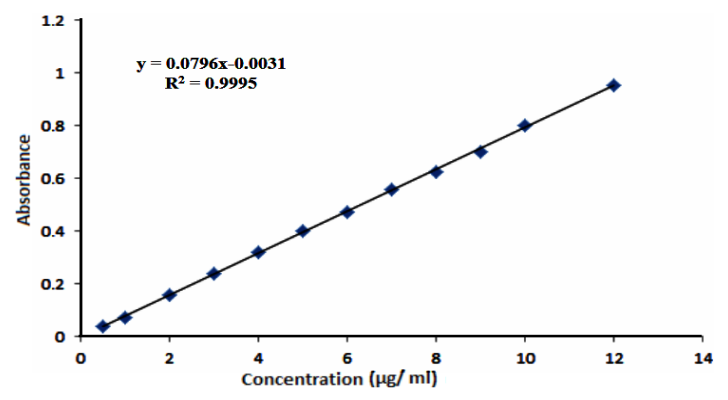

Fig. 7. Calibration curve at maximum wavelength $444 \mathrm{~nm}$

Table 1: Precision and accuracy of the calibration curve

\begin{tabular}{ccccc}
\hline Concentration of paracetamol $(\mu \mathrm{g} / \mathrm{mL})$ & Obtained by proposed method $(\mu \mathrm{g} / \mathrm{mL})$ & SD & RSD\% & E\% $^{*}$ \\
\hline 0.50 & 0.51 & $1.80 \times 10^{-4}$ & 0.48 & +2.00 \\
6.00 & 5.90 & $1.14 \times 10^{-4}$ & 0.02 & -1.70 \\
12.00 & 12.05 & $1.14 \times 10^{-4}$ & 0.01 & +0.40 \\
\hline
\end{tabular}

*Average of five determinations.

\section{Application and comparison}

The assessment of interferences in paracetamol pharmaceutical tablets and capsules are essential due to other ingredients that may cause an error in the assay ${ }^{14}$. Pure paracetamol of $6.00 \mu \mathrm{g} /$ $\mathrm{mL}$ is mixed with the interference solutions of $(30.00$ $\mu \mathrm{g} / \mathrm{mL})$ magnesium stearate, $(50.00 \mu \mathrm{g} / \mathrm{mL})$ starch, and $(70.00 \mu \mathrm{g} / \mathrm{mL})$ calcium carbonate, individually. The final volume of the prepared solutions was $25.00 \mathrm{~mL}$. A comparison was made between the spectra resulted of $6.00 \mu \mathrm{g} / \mathrm{mL}$ paracetamol standard solution and the interferences spectrum. Error more than $\pm 5 \%$ was unacceptable if the study of interference. Study of interferences was showed no significant levels that detected in the determination of paracetamol in the presence of the common ingredients of the medicine (Table 2).

Table 2: Interreferences and determination of paracetamol

\begin{tabular}{ccc}
\hline Interference & Acceptable amount added $(\mu \mathrm{g} / \mathrm{ml})$ & $\mathrm{E}^{*}$ \\
\hline Magnesium stearate & 30.00 & -2.90 \\
Starch & 50.00 & -0.06 \\
Calcium carbonate & 70.00 & -1.60 \\
\hline${ }^{*}$ Average of three determinations &
\end{tabular}


The results of paracetamol assessment in the pharmaceutical tablets was profitably bestowed. There were no interferences in the pharmaceutical tablets that affected the determination of paracetamol. Three pharmaceutical tablets were examined for analysis of paracetamol and was compared with the assay of standard paracetamol using HPLC. The results showed the appropriateness of the suggested procedure for the analysis of paracetamol in pharmaceutical tablets (Table 3). Isolation and assessment of pharmaceutical products using HPLC has been assessed in trace concentrations as low as parts per trillion ${ }^{4,6}$.

The calculated t- and F-values at 95\% confidence level, did not violate the theoretical values (Table 3 ). Wherefore, there is no overtone difference between the suggested method and the standard HPLC. Furthermore, uncomplicated, rapid, economical, and accurate spectrophotometric method was used in this work for determination of paracetamol in pharmaceutical tablets.

Table 3. Assessment of paracetamol in pharmaceutical tablets testing the suggested method and standard HPLC method

\begin{tabular}{|c|c|c|c|c|c|c|}
\hline $\begin{array}{c}\text { Pharmaceutical } \\
\text { tablet }\end{array}$ & $\begin{array}{c}\text { Content (mg/tablet) } \\
\text { declared }\end{array}$ & $\begin{array}{l}\text { Values of suggested } \\
\text { procedure (mg/tablet) }\end{array}$ & $\begin{array}{l}\text { Values of HPLC } \\
\text { (mg/tablet) }\end{array}$ & Recovery\% & $E \% *$ & $t$ and $F$ values ${ }^{\star *}$ \\
\hline S1 & 500 & $495.00 \pm 0.16$ & $500.50 \pm 0.08$ & 99 & -1.09 & $t=1.06, F=1.74$ \\
\hline S2 & 500 & $497.50 \pm 1.09$ & $499.50 \pm 0.15$ & 99.5 & -0.4 & $t=1.16, F=1.61$ \\
\hline S3 & 500 & $501.50 \pm 1.10$ & $501.00 \pm 0.09$ & 100.3 & 0.09 & $t=1.12, F=1.90$ \\
\hline
\end{tabular}

S1, S2 and S3 are pharmaceutical samples of three companies: Pioneer-Iraq, M.D.I.-Baghdad/Iraq, and Awamedica-Erbil/Iraq, respectively *Average of five determinations, ${ }^{*}$ Theoretical calculation of $t$ and $F$ at $95 \%$ confidence level $(n=5)$ was 2.78 and 6.39 , respectively, ${ }^{\star \star \star}$ The values \pm are the standard deviation of the five replications of each sample

In the articles, paracetamol was assessed with their parameters besides the suggested method. using various reagents and methods over Pre-extraction of the sample, easy and short time of the spectrophotometric technique. Table 4 is showed the reaction are the advantages of the suggested method determination of paracetamol various reagent reactions over some of the analytical method.

Table 4: Optimized results of paracetamol determination using different reagents and the suggested method

\begin{tabular}{lccc}
\hline Method based on & Reference & LR $(\mu \mathrm{g} / \mathrm{mL})$ & LOD $(\mu \mathrm{g} / \mathrm{mL})$ \\
\hline Glynn and Kendal & Bilel C., et al., 2020 & $40.00-400.00$ & 10 \\
sodium nitroprusside & Yanyan, Z., 2011 & $0.19-96.00$ & 0.01 \\
Derivative spectrophotometry & Rodenas,V., 2000 & $1.00-15.00$ & 0.14 \\
Suggested method & & $0.50-12.00$ & 0.05 \\
\hline
\end{tabular}

LR: Linear range, LOD: Limit of detection

\section{CONCLUSION}

Practicality of simplicity and rapidity are significant advantages of the suggested method for the assessment of paracetamol in pharmaceutical products. Besides, the free interferences of the suggested method from common tablet excipients. Stability of the colored reagent dye and time of reaction are allowed the analysis method to compose less brutal control of the experimental parameters. Economical reagent and easily reachable procedure that don't comprise any laborious sample preparation are characteristic for this work. These characteristics are upgraded the application of this work in routine quality control of paracetamol in industrial laboratories.

\section{ACKOWLDGMENT}

Authors are thankful for Department of Chemistry, Faculty of Science and Health, Koya University for providing the chemicals and the instrument to support this research work. Our thanks go to Awamedica pharmaceutical company in Erbil-Iraq for their support.

\section{Conflicts of interests}

All authors have none to declare. 


\section{REFERENCES}

1. Athersuch, T.J.; Antoine, D.J.; Boobis, A.R.; Coen, M.; Daly, A.K.; Possamai, L.; The Royal Society of Chemistry., 2018, 7(3), 347-57.

2. Kennon-McGrill, S.; McGrill, M.R.; J Clin Transl Res., 2017, 3(3), 297-310.

3. Bilel. C.; Anissa, Z.; Meriem, N.B.; Chaïmaa, R.; Haciba, R.; Toxicologie Analytique and Clinique., 2020, 326, 1-12.

4. Keerthisikha, P.; Sreenivasa, C.A.; Bharathi, K.; Spectrochimica Acta Part A: Molecular and Biomolecular Spectroscopy., 2020, 243, 118801.

5. Hewavitharana, A.K.; Lee, S.; Dawson, P.A.; Markovich, D.; Shaw, P.N.; Analytical Biochemistry., 2008, 374(1), 106-111.

6. Mahesh, A.; Pharmaceutical methods., 2011, 2(1), 61-66.

7. Yanyan, Z.; Yan, Z.; Quanmin, L.; Xinzhen, D.; Journal of Analytical Chemistry., 2011, 66
(2), 215-220.

8. Nagham, M. A.; Anal Bhiochem., 2015, 4(2), 1-4.

9. Kamla, M.E.; Hanna, M.W.; Nawal, A.K.; Marwa, F.B.; Bulletin Pharmaceutical Society., 2009, 32(2), 339-347.

10. Shah, J.; Jan, M.R.; Khan, M.A.; Journal of the Chinese Chemical Society., 2005, 52, 347-352.

11. Morrison, R.; Boyd, R.N.; Organic Chemistry. $6^{\text {th }}$ Ed. India: Prentice- Hall. 2002, 772-774.

12. Bruice, P.Y.; Organic Chemistry. $5^{\text {th }}$ ed., Prentice Hall India, 2004, 684-688.

13. International Conference on Harmonisation. 2005. Topic Q2 (R1): Validation of Analytical Procedures: Text and Methodology. International Conference on Harmonisation, Switzerland.

14. Yanyan, Z.; Yan, Z.; Quanmin, L.; Xinzhen, D.; Journal of Analytical Chemistry., 2011, 66(2), 215-220. 